\title{
Development of a new EGFR antibody antagonist which exhibits potential biological effects against laryngeal cancer
}

\author{
Kai Ren ${ }^{1}$, Binquan Wang', Qingyan $\mathbf{Q i}^{2}$ \\ ${ }^{1}$ Otolaryngology \& Head and Neck Surgery, First Hospital of Shanxi Medical University, Taiyuan, China; ${ }^{2}$ Medical Imaging Department, Shanxi Eye \\ Hospital, Taiyuan, China \\ Contributions: (I) Conception and design: K Ren; (II) Administrative support: B Wang; (III) Provision of study materials or patients: Q Qi; (IV) \\ Collection and assembly of data: K Ren; (V) Data analysis and interpretation: Q Qi; (VI) Manuscript writing: All authors; (VII) Final approval of \\ manuscript: All authors. \\ Correspondence to: Binquan Wang. Otolaryngology \& Head and Neck Surgery, First Hospital of Shanxi Medical University, Taiyuan 030001, China. \\ Email: Wbq_xy@sxent.org.
}

\begin{abstract}
Background: Laryngeal cancer is a common malignant tumor of the head and neck. Clinical treatment methods mainly include radiotherapy and chemotherapy, but the toxicity and side effects of these treatments seriously affect the quality of life of patients. Currently, there are no specific anti-laryngeal cancer drugs available. Therefore, it is necessary to develop new targeted drugs for laryngeal cancer.

Methods: We established a cell model of laryngeal cancer in vitro and a TU686 xenograft model in vivo. We then carried out the related research through a series of experiments [including laser confocal microscopy, enzyme linked immune sorbent assay (ELISA) and Western blot].

Results: The results showed that the epidermal growth factor receptor (EGFR) antibody antagonist 6E-C could not only specifically bind to EGFR, but also specifically inhibit the binding of EGF to EGFR. Further analysis indicated that $6 \mathrm{E}-\mathrm{C}$ could inhibit the EGFR-mediated intracellular signaling pathway. Furthermore, $6 \mathrm{E}-\mathrm{C}$ inhibited xenograft tumor growth in vivo.

Conclusions: In summary, we have successfully prepared a new anti-EGFR antibody antagonist, which exhibited anti-laryngeal cancer effects in vitro and in vivo. The current research demonstrates that the EGFR antibody antagonist $6 \mathrm{E}-\mathrm{C}$ shows potential as an effective anti-laryngeal cancer agent, with potential clinical application value. This study therefore provides a solid foundation for related research in the future.
\end{abstract}

Keywords: Epidermal growth factor receptor (EGFR); signaling; laryngeal cancer; antibody antagonist

Submitted Feb 25, 2021. Accepted for publication May 28, 2021.

doi: 10.21037/atm-21-1839

View this article at: http://dx.doi.org/10.21037/atm-21-1839

\section{Introduction}

Laryngeal cancer is a common malignant tumor of the human head and neck $(1,2)$. The clinical treatment methods mainly include radiotherapy and chemotherapy, but the toxicity and side effects of these treatments seriously affect the quality of life of patients $(3,4)$. Currently, there are no specific anti-laryngeal cancer drugs available. Therefore, scientists have been exploring targeted drugs for laryngeal cancer.

It is well known that epidermal growth factor (EGF) is closely related to tumor cell proliferation, angiogenesis, tumor invasion, metastasis, and apoptosis (5-7). Many studies have reported that the EGF receptor (EGFR) is overexpressed in head and neck cancers (such as laryngeal carcinoma). EGF interacts with EGFR to carry out its biological roles and functions. EGFR belongs to the tyrosine kinase receptor family. The family has 4 members: EGFR (ErbB1), ErbB2 (Her2), ErbB3 (Her3), and ErbB4 (Her4). These receptors can be activated by 7 ligands, such as EGF and transforming growth factor (TGF- $\alpha)(8,9)$. The first step in EGFR activation is the binding of EGF to 
EGFR, inducing EGFR to form a dimer, which in turn leads to EGFR autophosphorylation on multiple residues. EGFR activation further activates EGFR-mediated downstream signaling molecules, such as STAT3 and AKT $(10,11)$. Up to now, studies have shown that EGFR is overexpressed in laryngeal cancer tissues and is closely related to the proliferation of laryngeal cancer cells. Therefore, the development of EGFR antagonists may be a potential treatment option for laryngeal cancer. Traditionally, there are 2 strategies for the preparation of EGFR antagonists. One is to develop small-molecule EGFR tyrosine kinase inhibitors (EGFR-TKIs). For example, the first-generation EGFR-TKIs include gefitinib and erlotinib $(12,13)$. The mechanism of action of erlotinib is to inhibit the binding of the kinase domain, thereby blocking the EGFR-mediated signaling pathway and tumor cell proliferation. Another class of drugs is the anti-EGFR antibody drugs. The mechanism of action of this class of drugs is that they bind to the ligand binding site on EGFR, thereby inhibiting the proliferation and growth of tumor cells. However, due to the high mutation rate of EGFR, the sensitivity of different types of tumors to antibody drugs is inconsistent (10-13). Therefore, it is necessary to develop and screen new antibodies against EGFR based on tumor type.

In the current study, we developed and prepared a series of monoclonal antibodies against EGFR. We then performed a series of screening and identification experiments in laryngeal cancer cell lines, and found that 6E-C could inhibit EGFR-mediated signaling transduction both in vitro and in vivo. The current work demonstrates that the EGFR antibody antagonist $6 \mathrm{E}-\mathrm{C}$ shows potential as an effective anti-laryngeal cancer agent, which has laid a solid foundation for future research in this field. We present the following article in accordance with the ARRIVE reporting checklist (available at http://dx.doi.org/10.21037/ atm-21-1839).

\section{Methods}

\section{Antibodies and reagents}

Anti-EGFR antibody, anti-STAT3 antibody, anti-AKT antibody, and anti-ERK1/2 antibody were purchased from Abcam. Fetal calf serum (FCS) was obtained from Gibco (USA). Phospho-STAT3, phospho-AKT, and phospho-ERK1/2 antibodies were purchased from CST company (USA). Bovine Serum Albumin (BSA) and PVDF membranes were purchased from Beyotime
Biotechnology (Shanghai, China). Cell culture plates were purchased from Corning (New York, USA). DMEM, hypoxanthine-aminopterin-thymidine (HAT), and HT were purchased from Invitrogen (California, USA). The lowfluorescence PVDF membrane was purchased from BioRad Laboratories. Unless otherwise specified, reagents were obtained from Sigma-Aldrich Corp (St. Louis, MO, USA). Animal Experiments were performed under a project license (No.: 20200506) granted by animal ethics committee of First Hospital of Shanxi Medical University, in compliance with national guidelines for the care and use of animals.

\section{Cell culture}

TU686 cells were purchased from ATCC (American type culture collection). The cells were maintained in DMEM/ F12 (1:1) containing 10\% fetal bovine serum (FBS, Gibco) and $1 \%$ penicillin/streptomycin (Hyclone) at $37^{\circ} \mathrm{C}$ in a $5 \%$ $\mathrm{CO}_{2}$ incubator at saturated humidity.

\section{Preparation of the monoclonal antibody to EGFR}

EGFR and Freund's complete adjuvant were mixed and emulsified. Then, the mixture ( $\mu \mathrm{g} / \mathrm{mouse})$ was intraperitoneally injected into $\mathrm{BALB} / \mathrm{c}$ mice. A booster injection was administered using the same method and doses at 14-day intervals. The tail blood of immunized mice was sampled to determine antibody titer. When the antiEGFR titer reached 1:32,000, the spleen cells from mice with the highest titer were prepared. The spleen cells were then fused with mouse Sp2/0 myeloma cells at a ratio of 1:8 using $50 \%$ polyethylene glycol (PEG) 4000 . The fused cells were cultured in HAT selection medium containing 20\% FBS. After 10 days, antibody-producing cells were cultured in HT medium for another 7 days. Then, enzyme-linked immunosorbent assays (ELISA) were conducted to test the cell supernatants. The monoclonal antibody subtypes were identified using the mouse monoclonal antibody isotyping ( $\mathrm{mAb}$ ) ELISA kit according to the manufacturer's instructions.

\section{Indirect ELISA}

EGFR protein $(2 \mu \mathrm{g} / \mathrm{mL})$ was added to each well of a 96well sterile flat-bottom microplate. After incubation at $4{ }^{\circ} \mathrm{C}$ overnight, the plate was rinsed 3 times using PBST, and blocked with $5 \%$ sheep serum at $37^{\circ} \mathrm{C}$ for $1 \mathrm{~h}$. After washing, cell supernatant was added and incubated for 
another $2 \mathrm{~h}$ in a humidified incubator at $37^{\circ} \mathrm{C}$. After washing 3 times with PBST, HRP-labeled secondary antibody (1:2,000 dilutions) was added and incubated for another $1 \mathrm{~h}$ at $37^{\circ} \mathrm{C}$. After washing again, TMB solution was added and incubated at $37^{\circ} \mathrm{C}$ for $10 \mathrm{~min}$. Absorbance was read at $450 \mathrm{~nm}$ using a microplate reader (Bio-Rad).

In addition, the phosphorylated signal protein was detected using an ELISA kit according to the kit's instructions.

\section{Detection of cell proliferation by MTT}

TU686 cells were grown at $37^{\circ} \mathrm{C}$ to the logarithmic growth phase. The cells were then washed with PBS 3 times and digested. The cells were then harvested by centrifugation, and $1 \times 10^{4}$ cells were seeded into a 96-well cell culture plate. The different concentrations of anti-EGFR (6E-C) were added. The cells were cultured for 24, 48, and $72 \mathrm{~h}$. After washing cells 3 times, MTT solution was added and incubated for another $4 \mathrm{~h}$. The absorbance value of each well was checked with a microplate reader.

\section{Analysis of apoptosis by flow cytometry}

TU686 cells were grown at $37^{\circ} \mathrm{C}$ to the logarithmic growth phase. The cells were collected by centrifugation, and $1 \times 10^{6}$ cells were seeded into a cell culture flask and incubated for 24 h. Anti-EGFR (6E-C, $5 \mu \mathrm{g} / \mathrm{mL}$ ) or control antibody (6E-C, $5 \mu \mathrm{g} / \mathrm{mL}$ ) was added and incubated for $48 \mathrm{~h}$. After washing, the cell medium was discarded, and the cells were rinsed 3 times. Cells were fixed with $70 \%$ ethanol at $-20{ }^{\circ} \mathrm{C}$ for $2 \mathrm{~h}$. After 3 washes, the cells were collected by centrifugation. The cells were resuspended in $500 \mu \mathrm{L}$ PBS (containing $0.2 \%$ RNase A), and incubated at $37^{\circ} \mathrm{C}$ for $0.5 \mathrm{~h}$. The cells were then stained using an Annexin V-FITC/ PI staining kit (BD Pharmingen, San Diego, CA, USA). The cell samples were detected by flow cytometry (BD FACSCalibur Flow Cytometer).

\section{RT-PCR analysis}

The TU686 cells were collected, and total RNA was extracted using the Trizol kit according to the kit's instructions. UV spectrophotometry was used to determine the content and purity of the total RNA. The purified RNA was reverse transcribed into cDNA using oligo-dT-primers. The cDNA was used as a template for PCR amplification.
Bcl-2 mRNA levels were assayed by RT-qPCR using the following primers: fwd: 5'-CACTCAGCATATGGCGCAC GCTGGGAGAACGGGGTAC-3'; rvs: 5'-GCGAAGCTC TCGAGCTATCACCGCATGCTGGGGCCGTACAGT TC-3'. $\beta$-actin was used as the reference gene.

\section{Western blot}

The cells were collected, then the total cell proteins were extracted using lysis. The BCA kit was used to determine protein concentrations. The protein samples were separated by SDS-PAGE and transferred onto low-fluorescence PVDF (polyvinylidene fluoride) membranes. Membranes were washed 3 times, followed by blocking with 5\% BSA at $37{ }^{\circ} \mathrm{C}$ for $2 \mathrm{~h}$. After washing, the PVDF membranes were incubated with the indicated primary antibody $(1: 1,500$ dilutions) overnight at $4{ }^{\circ} \mathrm{C}$. The membranes were then washed 3 times in TBS-0.1\% Tween-20, and Alexa Fluor 488/555-conjugated secondary antibody (1:1,500 dilutions) was added and incubated for $2 \mathrm{~h}$ at $37^{\circ} \mathrm{C}$. After 3 washes with TBST, the PVDF membranes were detected by a fluorescence imaging system (Bio-Rad).

\section{Affinity determination by surface plasmon resonance (SPR)}

EGFR was coupled to a GLC chip via 1-ethyl-3-(3dimethylaminopropyl) carbodiimide hydrochloride. The different concentrations of antibodies were then injected. The dissociation constant $(\mathrm{Kd})$ was determined by the ProteOn XPR36 system.

\section{The effect of $6 E-C$ on TU686 migration}

TU686 cells were trypsinized and counted. Cells at $2 \times 10^{4} / \mathrm{mL}$ were seeded into the upper chamber of the transwell plate. Then, 6E-C was added into the upper chamber, and $600 \mu \mathrm{L}$ DMEM/F12 with $10 \%$ FBS was added into the lower chamber. The TU686 cells were cultured for $24 \mathrm{~h}$. The cells that remained in the upper chamber were removed, and cells on the bottom were stained with crystal violet solution. The cells were then observed under a microscope.

\section{Indirect immunofluorescence assay}

TU686 cells were grown to $30-50 \%$ confluence on cell slides. For routine immunostaining, the cells were washed and fixed with $4 \%$ paraformaldehyde for $15 \mathrm{~min}$ at RT, 
permeabilized with $0.5 \%$ triton for $15 \mathrm{~min}$, and blocked with $3 \%$ BSA for $0.5 \mathrm{~h}$. Primary antibodies were added to the cells and incubated overnight at $4{ }^{\circ} \mathrm{C}$. After washing, BSA-diluted secondary antibodies were added and incubated for $120 \mathrm{~min}$ at $37^{\circ} \mathrm{C}$. After 3 washes $(5 \mathrm{~min} /$ wash), the cell nuclei were stained with DAPI. The cell samples were observed and imaged using laser confocal microscopy (Olympus FV3000).

\section{Inbibition of the growth of TU686 xenografts by $6 E-C$}

A xenograft tumor model was established to analyze the in vivo effect of $6 \mathrm{E}-\mathrm{C}$ on laryngeal cancer. A total of $4 \times 10^{6}$ TU686 cells were injected into the flank of BALB/c nude mice. The mice were treated with $6 \mathrm{E}-\mathrm{C}$ when the tumor grew to a diameter of 3-5 $\mathrm{mm}$ (approximately $40-55 \mathrm{~mm}^{3}$ ). The nude mice were randomized into 3 groups $(n=5$ per group), and the mice were treated with vehicle, IgG1 (isotype control antibody), or 6E-C. Body weight and tumor size were measured using micrometer calipers. Tumor volume $(\mathrm{V})$ was calculated using the following standard formula: $[(D+d) / 2]^{3}$, where $D$ and $d$ were the larger and smaller diameters, respectively.

\section{Statistical analysis}

The data are presented as mean values \pm SD. Data were analyzed for statistical significance by one-way analysis of variance (ANOVA) using SPSS version 25.0. A P value of $<0.05$ was considered statistically significant.

\section{Results}

\section{Identification of the expression of EGFR in TU686 cells}

EGFR expression was evaluated by laser scanning confocal microscopy using a commercial EGFR antibody. As illustrated in Figure 1A, TU686 cells express abundant EGFR. Furthermore, flow cytometry analysis also indicated that high levels of EGFR were expressed in TU686 cells (Figure 1B).

\section{Preparation and identification of the anti-EGFR antibody}

After 4 immunizations, the spleen cells from immunized mice were fused with $\mathrm{Sp} 2 / 0$ myeloma cells. In total, we screened 69 monoclonal antibodies against EGFR, among which an anti-EGFR monoclonal antibody was selected for further identification (termed 6E-C, IgG1 subclass). To further characterize whether $6 \mathrm{E}-\mathrm{C}$ could interact with EGFR, the following experiments were performed: (I) indirect immunofluorescence showed that $6 \mathrm{E}-\mathrm{C}$ could bind to TU686 cells (Figure 2A); (II) colocalization analysis showed that $6 \mathrm{E}-\mathrm{C}$ could specifically bind to EGFR (Figure 2B); (III) to further demonstrate that 6E-C could specifically bind to EGFR, a competitive receptor binding analysis was performed on TU686 cells by flow cytometry, which indicated that non-fluorescently labeled EGF and 6E-C could inhibit fluorescently labeled-EGF from binding to EGFR in TU686 cells (Figure 2C). However, the control antibody had no effect in these experiments. Biacore analysis was performed with immobilized $6 \mathrm{E}-\mathrm{C}$, and the results showed an affinity of $2.0 \times 10^{-9} \mathrm{~mol} / \mathrm{L}$ for EGFR.

\section{Analysis of the effect of $6 E-C$ on TU686 cell proliferation using the MTT assay}

The effect of $6 \mathrm{E}-\mathrm{C}$ on TU686 cell proliferation was evaluated using the MTT assay. As shown in Figure $3 A$, 6E-C (but not the control antibody) could significantly inhibit TU686 cell proliferation.

In addition, we also analyzed the effect of $6 \mathrm{E}-\mathrm{C}$ on the expression of apoptosis-associated genes (Bcl-2 and $\mathrm{Bax})$, and the results showed that $6 \mathrm{E}-\mathrm{C}$ down-regulated the expression of $\mathrm{Bcl}-2$ and up-regulated the expression of Bax (Figure 3B). Additionally, caspase-3 expression was also up-regulated by $6 \mathrm{E}-\mathrm{C}$ treatment (Figure $3 C$ ). We also evaluated the effect of $6 \mathrm{E}-\mathrm{C}$ on TU686 cell migration, and the results showed that $6 \mathrm{E}-\mathrm{C}$ inhibited TU686 cell migration (Figure 3D).

\section{Inbibition of the EGFR-mediated intracellular signaling patbway by $6 E-C$}

We first tested whether $6 \mathrm{E}-\mathrm{C}$ itself had agonistic activity by western blot, and results showed that $6 \mathrm{E}-\mathrm{C}$ had no agonistic activities (Figure 4A). Next, we analyzed the antagonistic activity of $6 \mathrm{E}-\mathrm{C}$ by flow cytometry, which showed that 6E-C significantly inhibited the EGF/EGFR-mediated intracellular signaling pathway in a dose-dependent manner, and $6 \mathrm{E}-\mathrm{C}(5 \mu \mathrm{g} / \mathrm{mL})$ almost completely inhibited EGFRinduced intracellular signaling (Figure $4 B$ ).

\section{The effect of 6E-C on the cell cycle and apoptosis}

We analyzed the effect of $6 \mathrm{E}-\mathrm{C}$ on the cell cycle and 
A

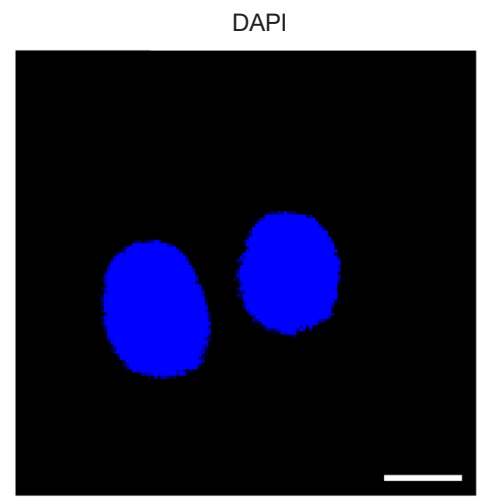

B

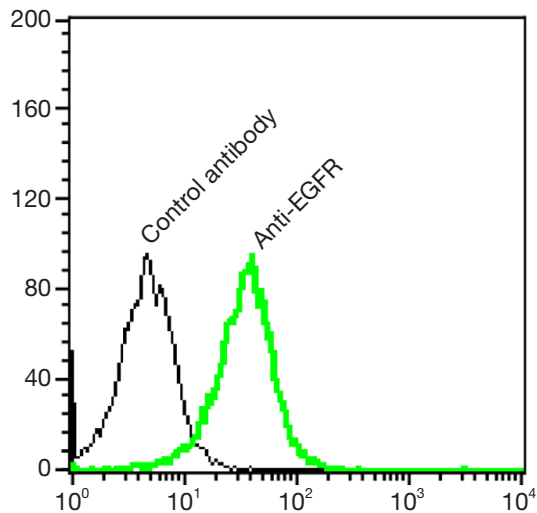

EGFR

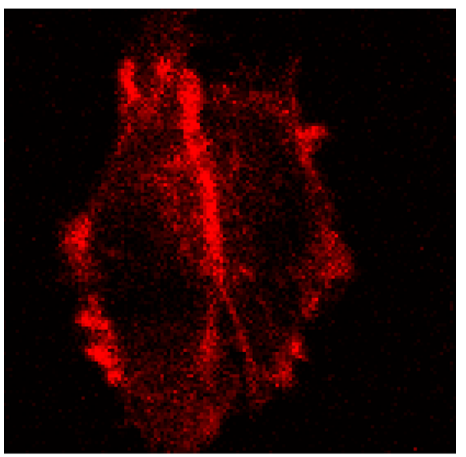

Merge

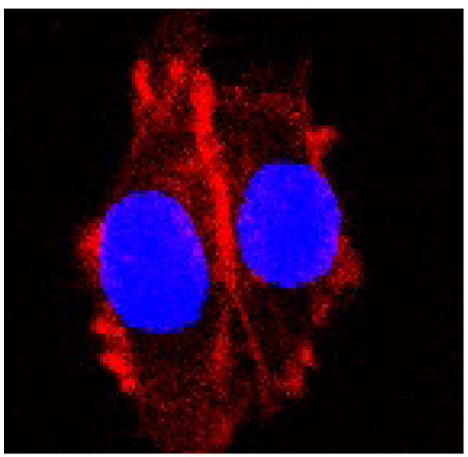

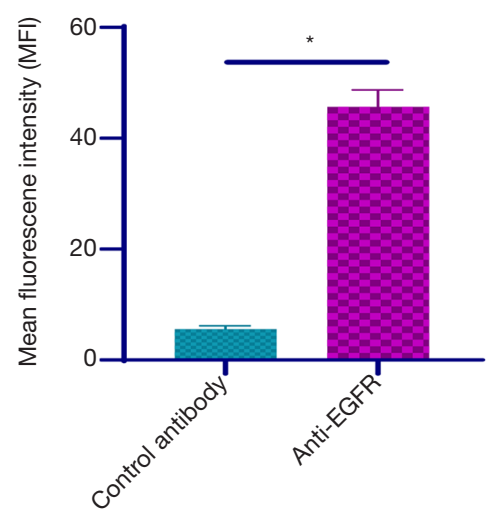

Figure 1 Evaluation of the expression of EGFR. (A) Analysis of EGFR expression by CLSM. (B) TU686 cells express abundant EGFR as determined by flow cytometry analysis. Data are expressed as mean and standard deviation. An asterisk indicates a statistically significant difference $(\mathrm{P}<0.05)$. Bar $=10 \mu \mathrm{m}$. EGFR, epidermal growth factor receptor; CLSM, confocal laser scanning microscope.

apoptosis of TU686 cells, and the results showed that $6 \mathrm{E}-\mathrm{C}(5-10 \mu \mathrm{g} / \mathrm{mL})$ altered the cell cycle of TU686 cells, as the proportion of S-phase cells was significantly reduced (Figure 5A). Furthermore, flow cytometry analysis showed that $6 \mathrm{E}-\mathrm{C}$ significantly increased TU686 cell apoptosis compared to the control antibody (Figure 5B).

\section{E-C inhibited xenograft tumor growth in vivo}

A laryngeal cancer xenograft model was established to evaluate the anti-tumor effect of $6 \mathrm{E}-\mathrm{C}$ in vivo. As indicated in Figure 6A, 6E-C (but not the control antibody) inhibited laryngeal cancer xenograft growth (Figure 6). These findings showed that $6 \mathrm{E}-\mathrm{C}$ has a good anti-tumor effect in vivo in nude mice.

\section{The effect of 6E-C on EGFR-mediated intracellular signaling in vivo}

As shown in Figure 7, 6E-C, but not the control antibody, down-regulated the levels of p-EGFR, P-STAT3, and p-AKT in the xenograft tumor (Figure $7 A$ ). We evaluated the cell proliferation of laryngeal cancer tissue by the detection of Ki67, a cell proliferation marker, and results indicated that the percentage of Ki67-positive cells was significantly reduced compared to the control antibody (Figure 7B).

\section{E-C cellular behavior}

The cellular behavior of $6 \mathrm{E}-\mathrm{C}$ was tested, and results showed that $6 \mathrm{E}-\mathrm{C}$ was internalized into cells in a time- 
A

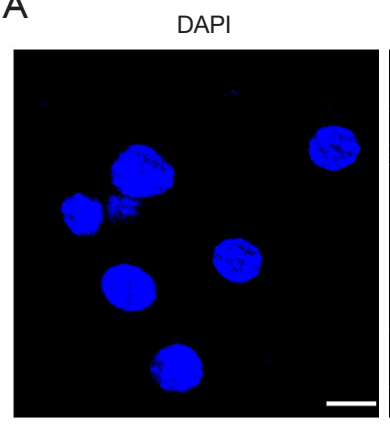

$6 \mathrm{E}-\mathrm{C}$

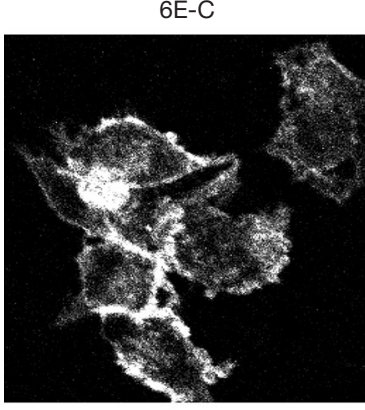

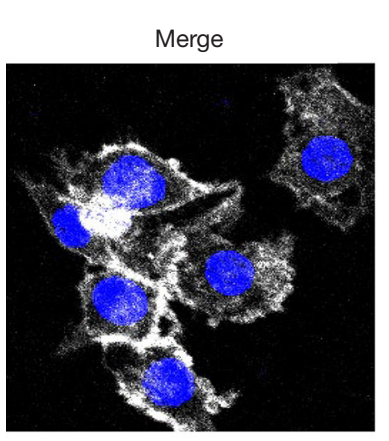

C

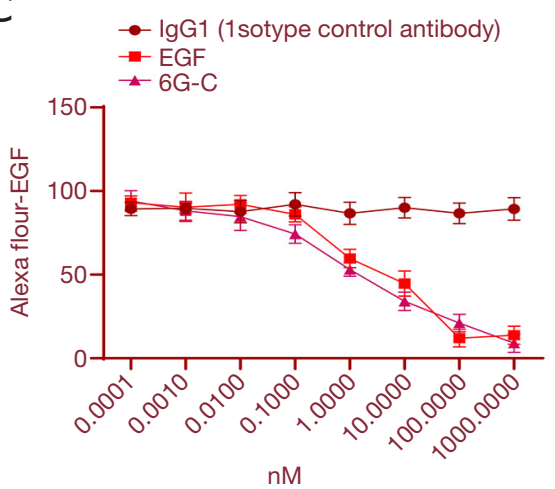

B

$6 \mathrm{E}-\mathrm{C}$

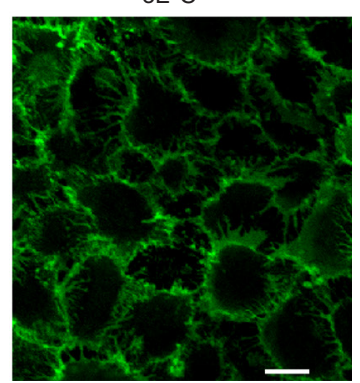

EGFR

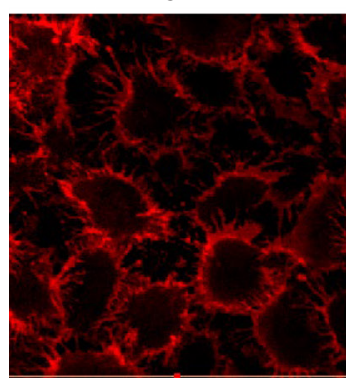

6E-C/EGFR

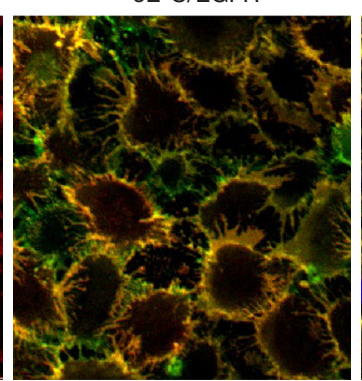

Merge

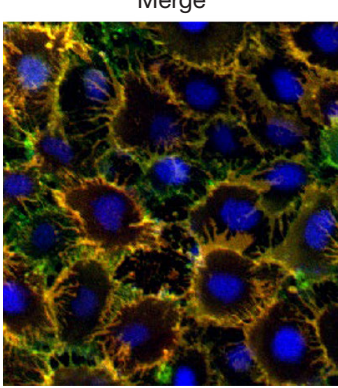

Colocalization analysis

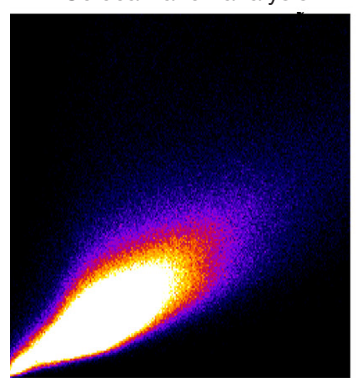

Figure 2 Analysis of interaction between 6E-C and EGFR. (A) 6E-C binds to TU686 cells as shown by the IFA assay. (B) 6E-C binding to EGFR as determined by colocalization analysis. (C) 6E-C could specifically bind to EGFR in TU686 cells as seen through competitive receptor binding analysis. Data are expressed as mean and standard deviation. Bar $=10 \mu \mathrm{m}$. EGFR, epidermal growth factor receptor.

dependent manner. At 0-1 min, 6E-C was mainly localized on the cell membrane. Cytoplasmic fluorescence was gradually increased at $30 \mathrm{~min}$, fluorescence intensity reached a maximum value at $60 \mathrm{~min}$, and then the fluorescence intensity began to decline (Figure 8).

\section{Discussion}

Laryngeal cancer is a common malignant tumor of the head and neck $(14,15)$. It has been reported that laryngeal cancer occurs mainly in smoking men (16). The clinical treatment methods mainly include radiotherapy and chemotherapy, and no specific anti-laryngeal cancer drugs are available. Therefore, it is necessary to develop targeted drugs for laryngeal cancer. Under normal circumstances, EGF/EGFR has important biological activities, including the regulation of growth and development. From this point of view, EGF/ EGFR is a very important biomolecule (17). However, a series of studies have shown that EGFR is closely related to the occurrence and development of laryngeal cancer. For this reason, in the current study, we developed an antibody inhibitor against laryngeal cancer with EGFR as the target (6E-C). This work showed that $6 \mathrm{E}-\mathrm{C}$ had good antagonistic effects.

Although researchers have developed many EGFR antibody antagonists, the EGFR mutation rate is high (18-21). Therefore, it is necessary to develop specific EGFR antibody antagonists for different types of tumors. In this study, we prepared and screened a total of 69 monoclonal antibodies against EGFR, among which the anti-EGFR monoclonal antibody $6 \mathrm{E}-\mathrm{C}$ was selected for further identification. The results showed that $6 \mathrm{E}-\mathrm{C}$ could not only specifically bind to EGFR, but also specifically inhibited the binding of EGF to EGFR. Further analysis showed that $6 \mathrm{E}-\mathrm{C}$ could inhibit the EGFR-mediated intracellular signaling pathway.

At present, there are 2 types of EGFR antagonists. One class of molecules are anti-EGFR antibodies, such as cetuximab $(21,22)$. Cetuximab $(152-\mathrm{kDa}$ molecule), an antiEGFR human-mouse chimeric IgG1 monoclonal antibody, 
A

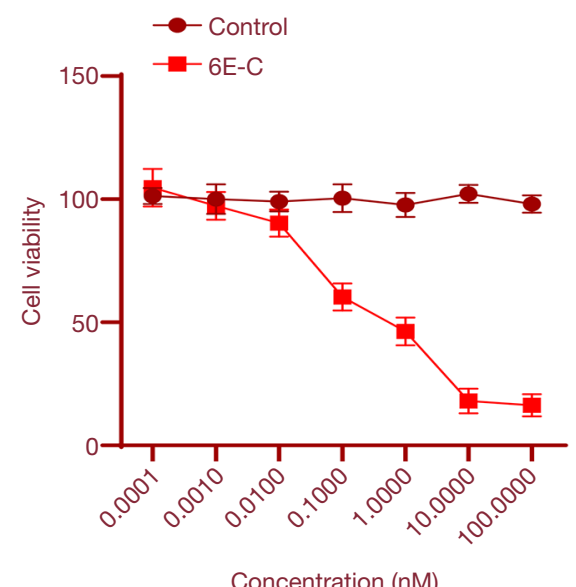

D

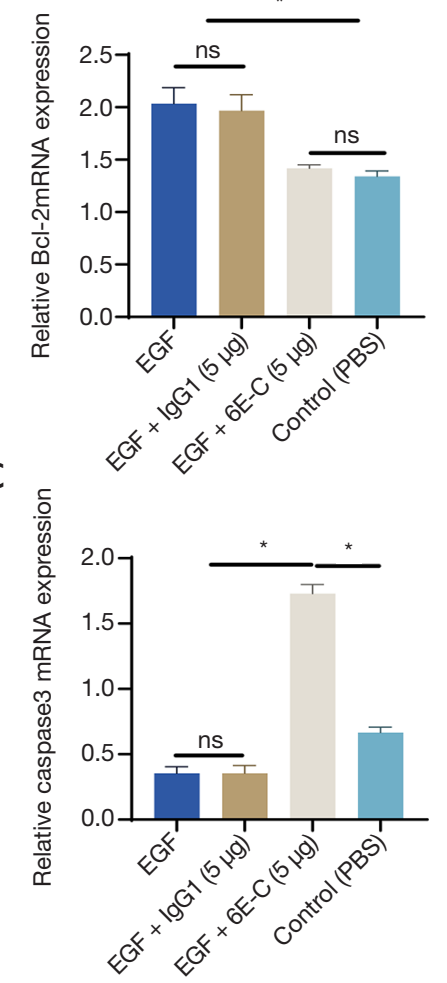

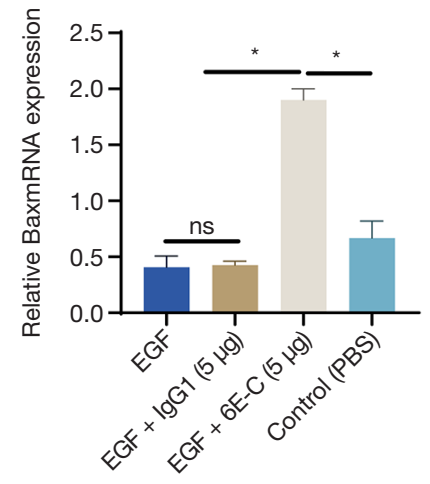

$\mathrm{D}$
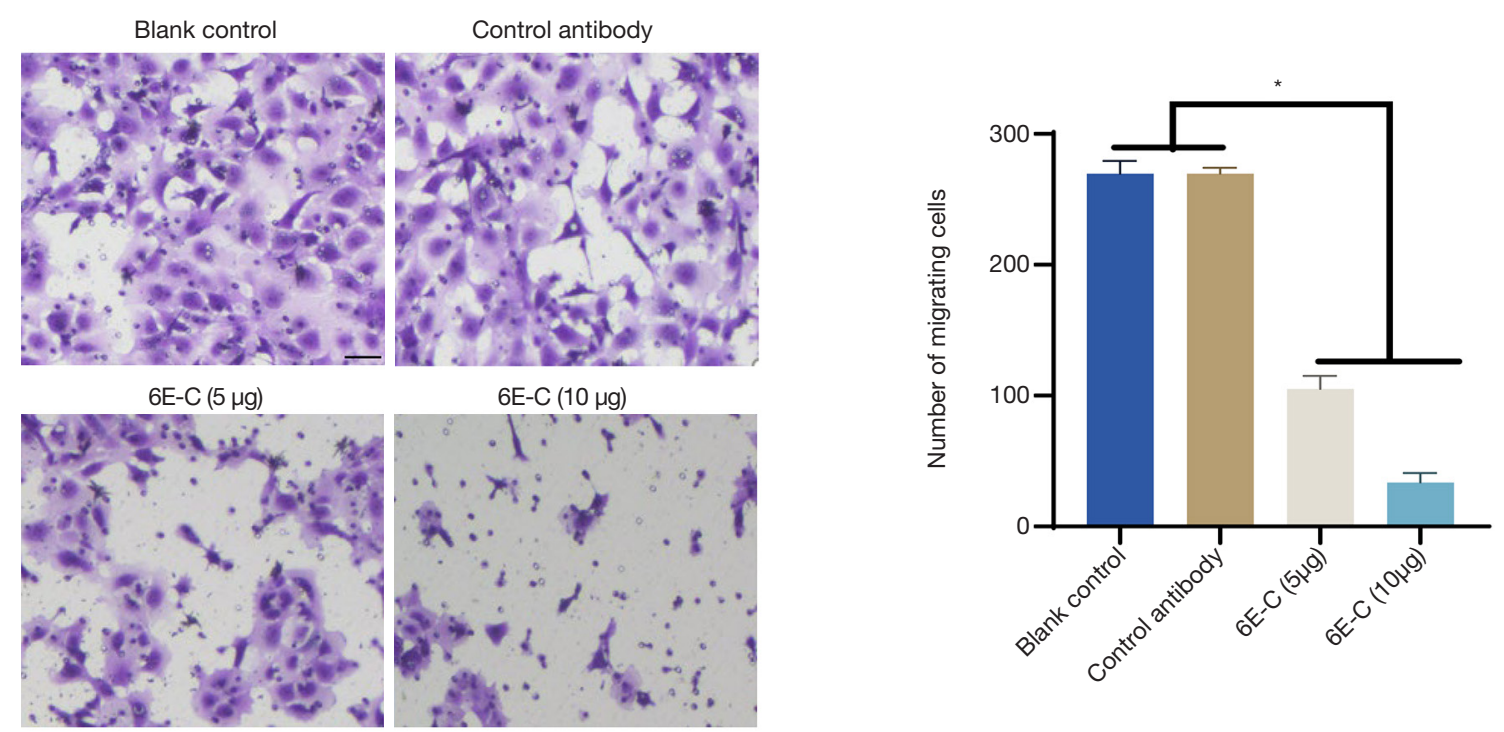

Figure 3 Analysis of the biological activity of 6E-C. (A) The effect of 6E-C on TU686 cell proliferation determined using the MTT assay. (B) The effect of $6 \mathrm{E}-\mathrm{C}$ on the expression of Bcl-2 and Bax. (C) Caspase-3 expression was also up-regulated by $6 \mathrm{E}-\mathrm{C}$ treatment. (D) The effect of $6 \mathrm{E}-\mathrm{C}$ on TU686 cell migration. The non-migrated cells in the upper chamber were removed, the cells in the lower chamber stained with crystal violet. Data are expressed as mean and standard deviation. An asterisk $\left(^{*}\right)$ indicates a statistically significant difference $(\mathrm{P}<0.05)$. Bar $=50 \mu \mathrm{m}$. ns, not statistically significant. 
A
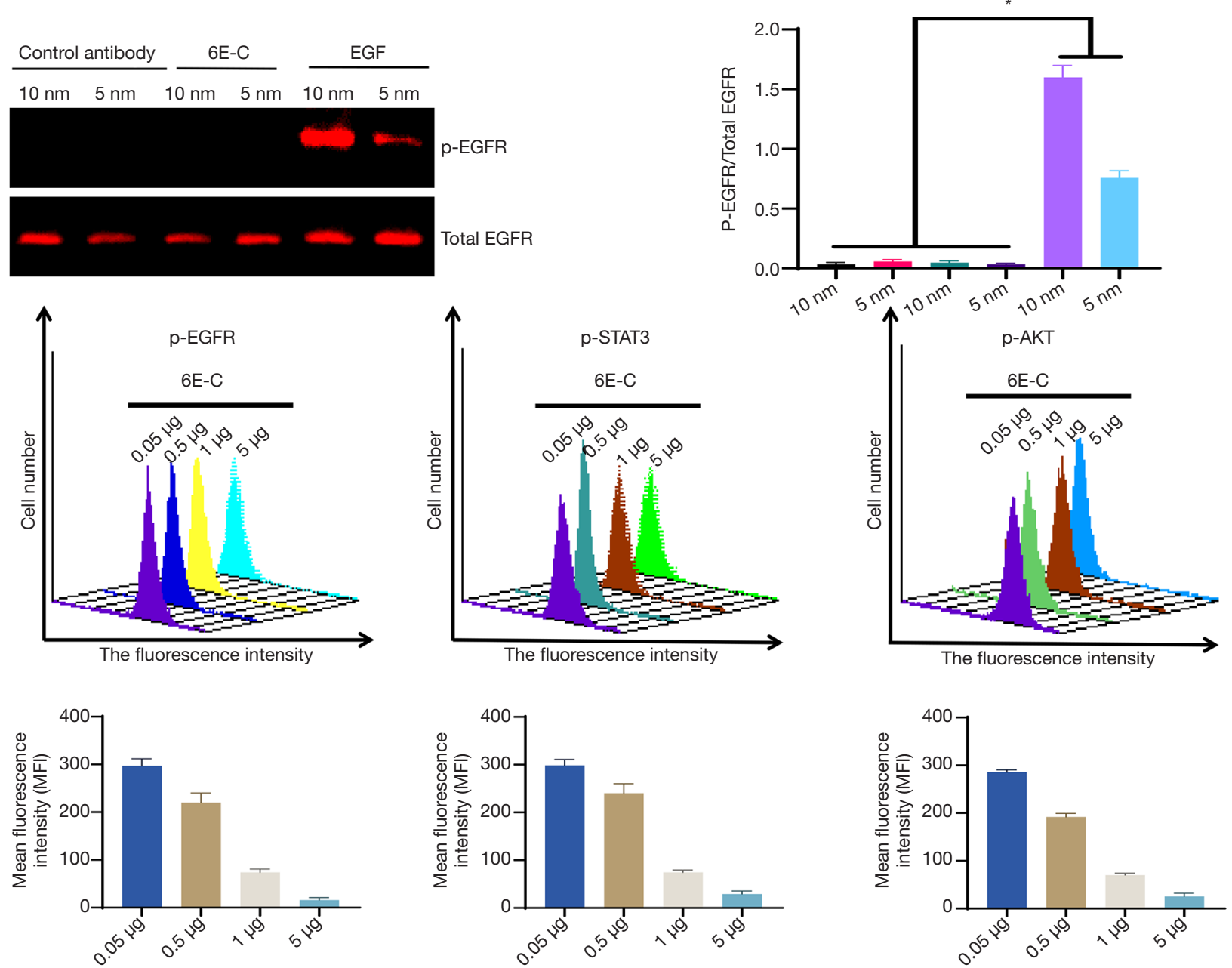

Figure 4 Evaluation of agonistic activity of 6E-C. (A) 6E-C itself has no agonistic activity determined by Western blot analysis. The experiment has been described in detail in the materials and methods section. (B) 6E-C inhibited EGFR-mediated intracellular signaling in a dose-dependent manner. Data are expressed as mean and standard deviation. An asterisk $\left(^{*}\right)$ indicates a statistically significant difference $(\mathrm{P}<0.05)$. EGFR, epidermal growth factor receptor.

contains the human IgG1 constant region. Cetuximab can inhibit endogenous ligands from binding to EGFR expressed on the cell membrane. Furthermore, it has been reported that cetuximab could promote the internalization and degradation of EGFR. In addition, cetuximab exhibited antibody-dependent cellular cytotoxicity against EGFRexpressing cancer cells. The other types of inhibitors are the EGFR-TKIs. These inhibitors can limit ATP from binding to the intracellular tyrosine kinase domain of EGFR, thereby inhibiting EGFR activation. Subsequently, the EGFR-mediated downstream signaling pathway is blocked. Gefitinib and erlotinib are the first generation of EGFR-TKIs. Recently, a new EGFR antagonist was developed. Wang et al. reported that they developed a new EGFR inhibitor using the anti-idiotypic antibody strategy according to Jerne's idiotypic network theory of the immune system. They prepared an EGFR antagonist (FG8) using hybridoma technology via a series of immunological protocols (23). They found that FG8 could compete with EGF to bind to EGFR. Further research found that FG8 could inhibit the intracellular signaling pathway mediated by EGFR, indicating that FG8 is a potential strategy for the preparation of EGFR antagonists. However, anti-idiotypic antibodies also have their own shortcomings, such as very weak affinity, which is a problem that needs to be solved.

EGFR is closely related to the occurrence and 
A

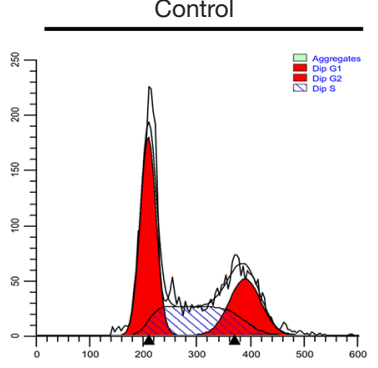

B

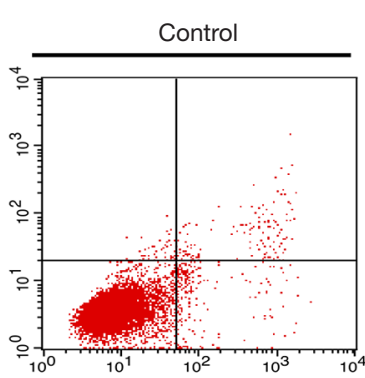

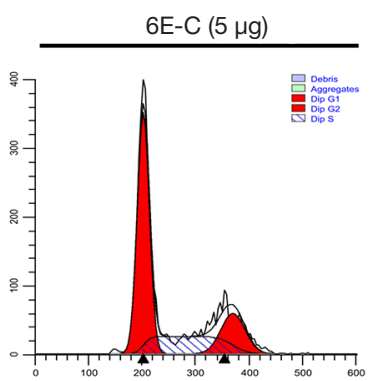

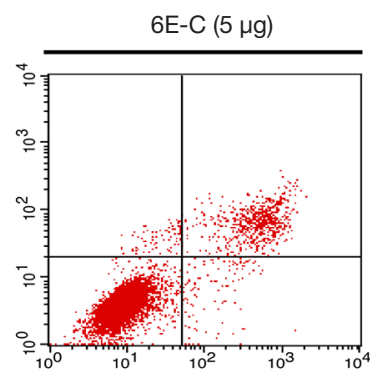

$6 \mathrm{E}-\mathrm{C}(10 \mu \mathrm{g})$
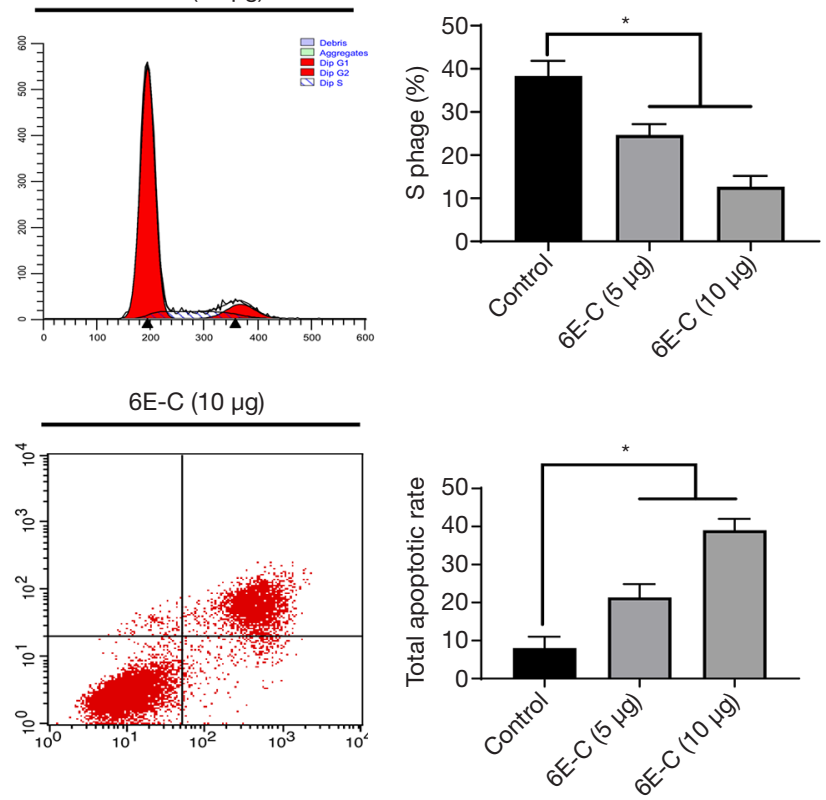

Figure 5 Assessment of the agonistic effect of 6E-C. (A) 6E-C altered the cell cycle of TU686 cells. The experiment has been described in detail in the materials and methods section. (B) 6E-C significantly increased TU686 cell apoptosis. Data are expressed as mean and standard deviation. An asterisk $\left.{ }^{*}\right)$ indicates a statistically significant difference $(\mathrm{P}<0.05)$.

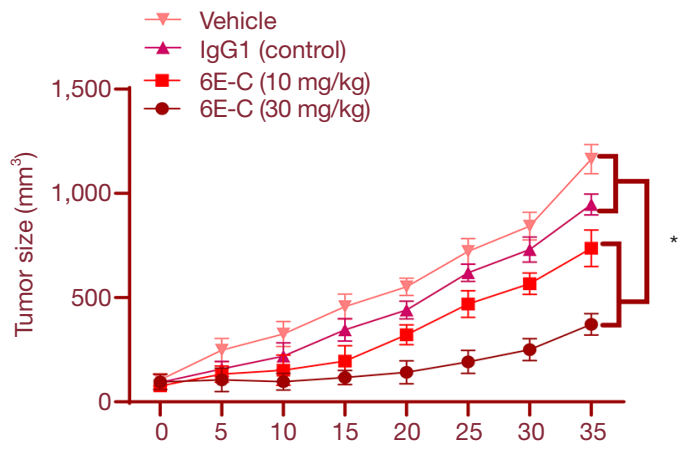

Figure 6 Inhibition of laryngeal cancer xenograft growth by 6E-C. Data are expressed as mean and standard deviation. An asterisk (*) indicates a statistically significant difference $(\mathrm{P}<0.05)$.

development of a series of tumors (18). It has been reported that EGRF is significantly up-regulated in many types of tumor cells, such as non-small cell lung cancer, head and neck squamous cell carcinoma, colorectal cancer, breast cancer, and brain cancer (18). Therefore, $6 \mathrm{E}-\mathrm{C}$ has good application potential in the future, and related experiments are ongoing in our lab.

It is well known that the cellular behavior of EGF/EGFR is closely related to its biological activities (24). Therefore, we analyzed the cellular properties of $6 \mathrm{E}-\mathrm{C}$ and found that $6 \mathrm{E}-\mathrm{C}$ could internalize into cells, suggesting that $6 \mathrm{E}-\mathrm{C}$ could induce EGFR degradation.

In summary, in the current study, we prepared a monoclonal antibody against EGFR, and found that $6 \mathrm{E}-\mathrm{C}$ could inhibit EGFR-mediated signaling transduction in in vitro experiments. Furthermore, $6 \mathrm{E}-\mathrm{C}$ has good anti- 
A
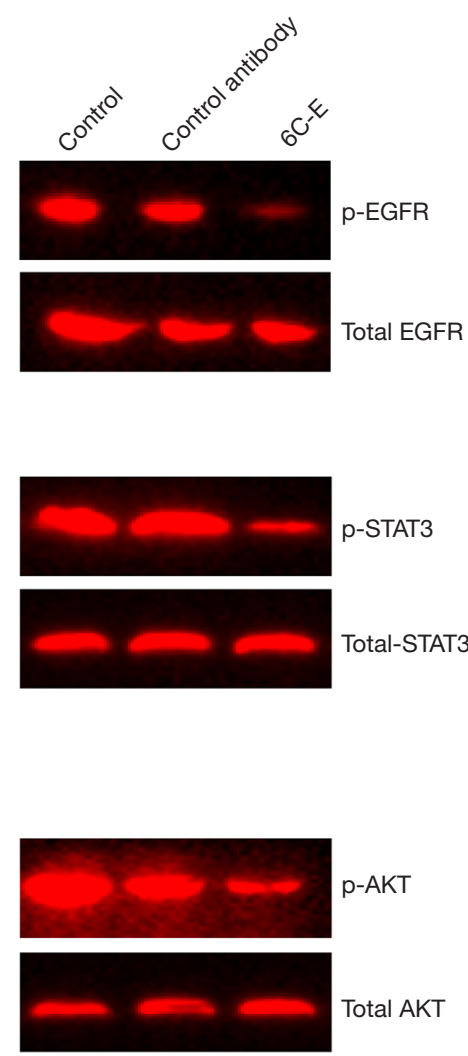
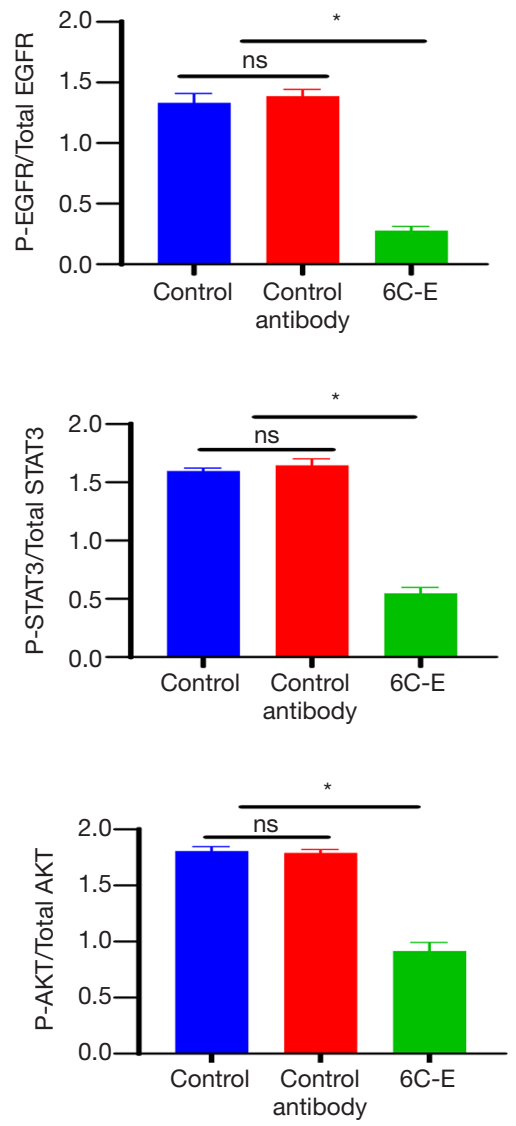

B

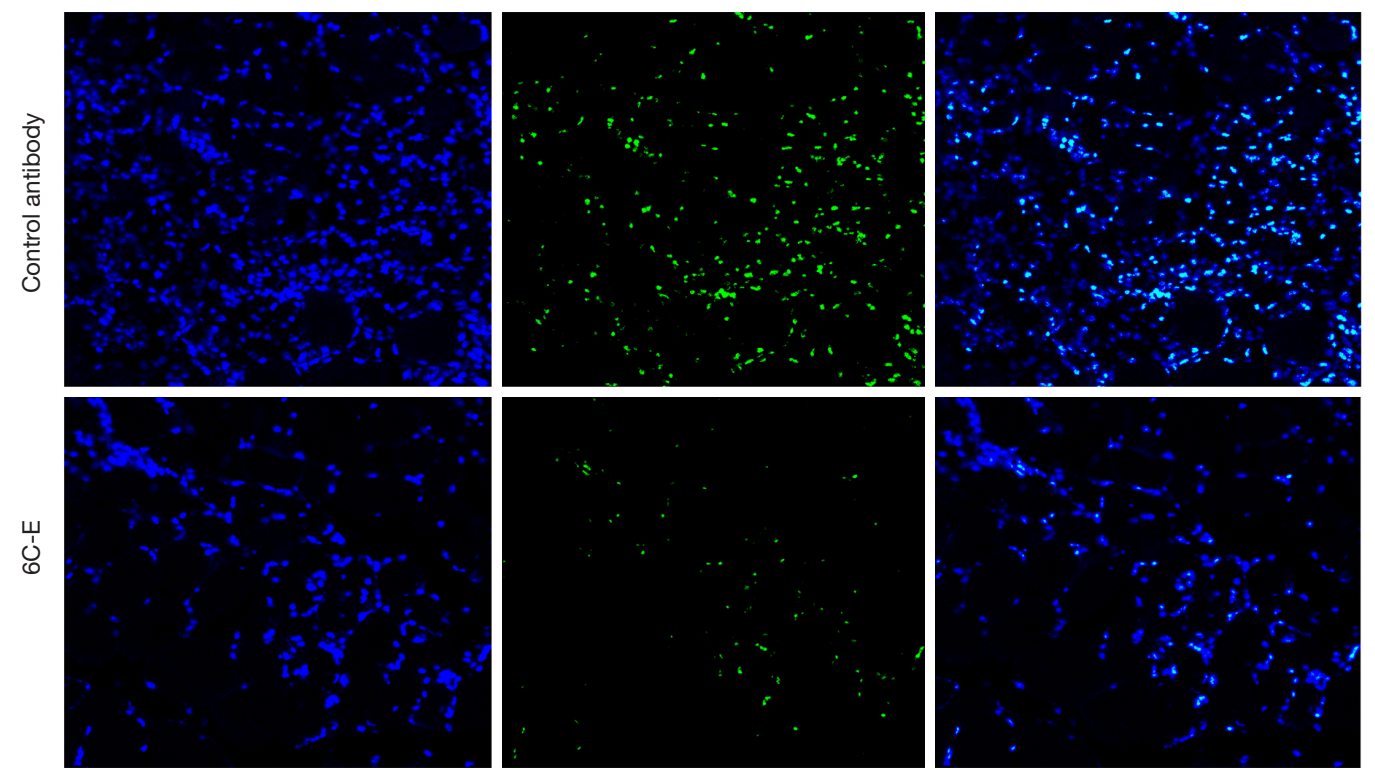

Figure 7 The effect of $6 \mathrm{E}-\mathrm{C}$ on EGFR. (A) $6 \mathrm{E}-\mathrm{C}$ down-regulated the levels of p-EGFR, P-STAT3, and p-AKT. (B) The percentage of cells positive for Ki67, a cell proliferation marker, was significantly reduced by $6 \mathrm{E}-\mathrm{C}$ treatment. Data are expressed as mean and standard deviation. An asterisk indicates a statistically significant difference $(\mathrm{P}<0.05)$. Bar $=50 \mu \mathrm{m}$. EGFR, epidermal growth factor receptor; ns, not statistically significant. 

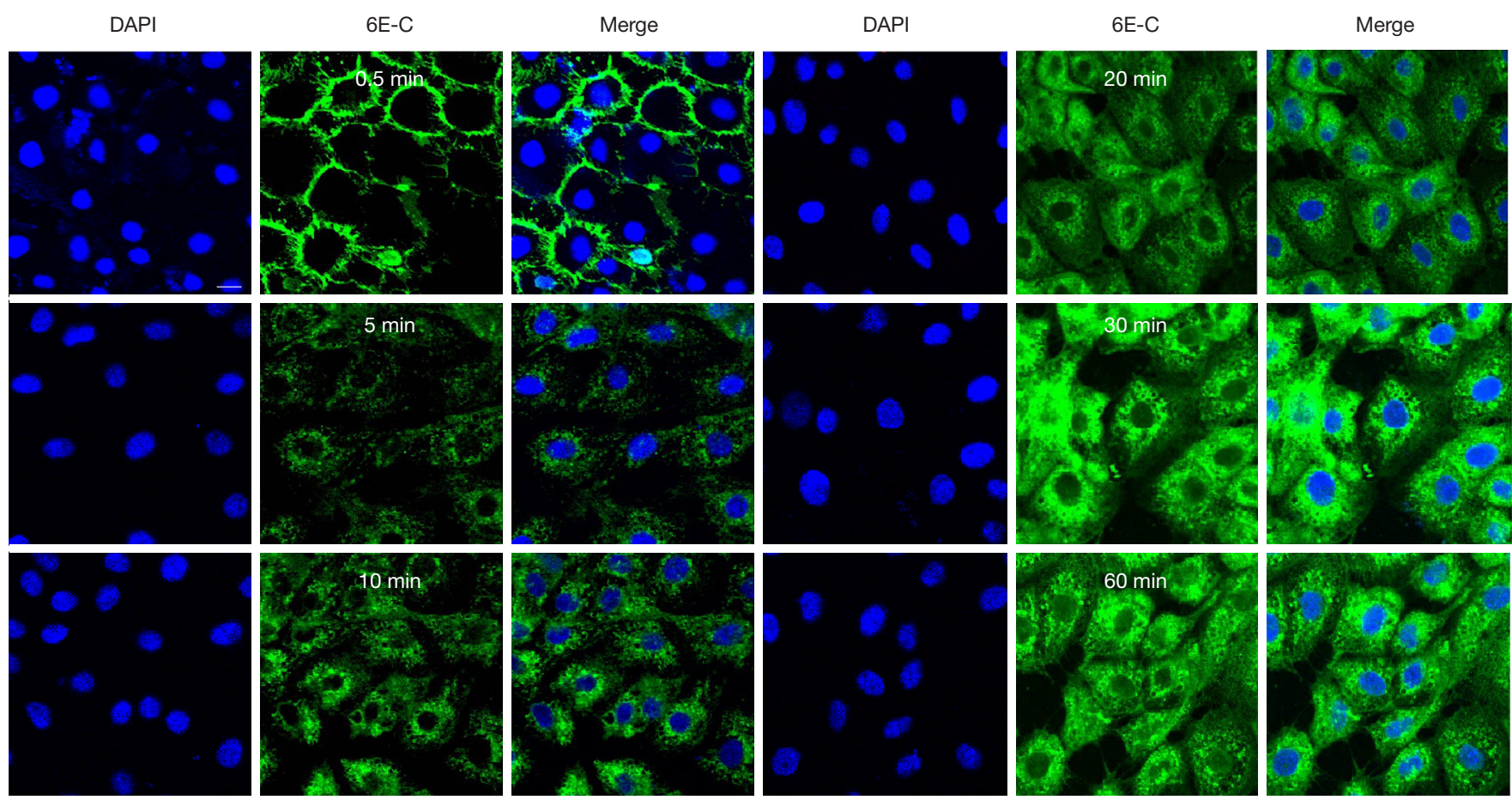

Figure 8 The cellular behaviour of $6 \mathrm{E}-\mathrm{C}$. The experiment process has been described in detail in the materials and methods section. Bar $=10 \mu \mathrm{m}$.

tumor effects in vivo in nude mice. The current research shows that the EGFR antibody antagonist $6 \mathrm{E}-\mathrm{C}$ has good potential for the treatment of laryngeal cancer.

\section{Acknowledgments}

We thank Professor Zhang for her help in the CLSM experiments.

Funding: None.

\section{Footnote}

Reporting Checklist: The authors have completed the ARRIVE reporting checklist. Available at http://dx.doi. org/10.21037/atm-21-1839

Data Sharing Statement: Available at http://dx.doi. org/10.21037/atm-21-1839

Conflicts of Interest: All authors have completed the ICMJE uniform disclosure form (available at http://dx.doi. org/10.21037/atm-21-1839). The authors have no conflicts of interest to declare.
Ethical Statement: The authors are accountable for all aspects of the work in ensuring that questions related to the accuracy or integrity of any part of the work are appropriately investigated and resolved. Animal Experiments were performed under a project license (No.: 20200506) granted First Hospital of Shanxi Medical University, in compliance with national guidelines for the care and use of animals.

Open Access Statement: This is an Open Access article distributed in accordance with the Creative Commons Attribution-NonCommercial-NoDerivs 4.0 International License (CC BY-NC-ND 4.0), which permits the noncommercial replication and distribution of the article with the strict proviso that no changes or edits are made and the original work is properly cited (including links to both the formal publication through the relevant DOI and the license). See: https://creativecommons.org/licenses/by-nc-nd/4.0/.

\section{References}

1. Fullmer T, Wilde DC, Shi JW, et al. Demographic and Tumor Characteristic Impact on Laryngeal Cancer 
Outcomes in a Minority Underserved Patient Population. Otolaryngol Head Neck Surg 2020;162:888-96.

2. Shen J, Hu K, Ma J, et al. Clinical analysis of EBRT vs TLM in the treatment of early (T1-T2N0) glottic laryngeal cancer. J Cancer 2020;11:6686-94.

3. Blood T. Laryngeal Cancer. Dedivitis RA, Peretti G, Hanna E, et al. Thieme Medical Publishers, Inc., New York, NY, 2019, 183 pages, \$139.99 USD. Head Neck 2020;42:141-2.

4. Rizzo MI, Ralli M, Nicolazzo C, et al. Detection of circulating tumor cells in patients with laryngeal cancer using ScreenCell: Comparative pre- and post-operative analysis and association with prognosis. Oncol Lett 2020;19:4183-8.

5. Dunn IF, Heese O, Black PM. Growth factors in glioma angiogenesis: FGFs, PDGF, EGF, and TGFs. J Neurooncol 2000;50:121-37.

6. Guo W, Pylayeva Y, Pepe A, et al. Beta 4 integrin amplifies erbb2 signaling to promote mammary tumorigenesis. Cell 2006;126:489-502.

7. Wang D, Xu S, Lin Y, et al. Recombinant porcine epidermal growth factor-secreting Lactococcus lactis promotes the growth performance of early-weaned piglets. BMC Vet Res 2014;10:171.

8. Bouyain S, Longo PA, Li S, et al. The extracellular region of erbb4 adopts a tethered conformation in the absence of ligand. Proc Natl Acad Sci U S A 2005;102:15024-9.

9. Hobbs SS, Cameron EM, Hammer RP, et al. Five carboxyl-terminal residues of neuregulin2 are critical for stimulation of signaling by the erbb4 receptor tyrosine kinase. Oncogene 2004;23:883-93.

10. Mizoguchi M, Betensky RA, Batchelor TT, et al. Activation of STAT3, MAPK, and AKT in malignant astrocytic gliomas: correlation with EGFR status, tumor grade, and survival. J Neuropathol Exp Neurol 2006;65:1181-8.

11. Huang Q, Li S, Zhang L, et al. CAPE-pNO2Inhibited the Growth and Metastasis of Triple-Negative Breast Cancer via the EGFR/STAT3/Akt/E-Cadherin Signaling Pathway. Front Oncol 2019;9:461.

12. Xu Y, Liu H, Chen J, et al. Acquired resistance of lung adenocarcinoma to EGFR-tyrosine kinase inhibitors gefitinib and erlotinib. Cancer Biol Ther 2010;9:572-82.

13. Wang YC, Kulp SK, Wang D, et al. Targeting endoplasmic reticulum stress and Akt with OSU-03012 and gefitinib or erlotinib to overcome resistance to epidermal growth factor receptor inhibitors. Cancer Res 2008;68:2820-30.

14. Saedi B, Razmpa E, Sadeghi M, et al. The epidemiology of laryngeal cancer in a country on the esophageal cancer belt.
Indian J Otolaryngol Head Neck Surg 2009;61:213-7.

15. Tian J, Wang BQ. A contemporary review of the surgical margins in laryngeal carcinoma. Lin Chung Er Bi Yan Hou Tou Jing Wai Ke Za Zhi 2018;32:1594-9.

16. Jee $\mathrm{SH}$, Kim M, Kim M, et al. Clinical relevance of glycerophospholipid, sphingomyelin and glutathione metabolism in the pathogenesis of pharyngolaryngeal cancer in smokers: the Korean Cancer Prevention StudyII. Metabolomics 2016;12:164.

17. Diaz Miqueli A, Blanco R, Garcia B, et al. Biological activity in vitro of anti-epidermal growth factor receptor monoclonal antibodies with different affinities. Hybridoma (Larchmt) 2007;26:423-31.

18. Wu CC, Hsu HY, Liu HP, et al. Reversed mutation rates of KRAS and EGFR genes in adenocarcinoma of the lung in Taiwan and their implications. Cancer 2008;113:3199-208.

19. Hu C, Liu X, Chen Y, et al. Direct serum and tissue assay for EGFR mutation in non-small cell lung cancer by highresolution melting analysis. Oncol Rep 2012;28:1815-21.

20. Lu RL, Hu CP, Yang HP, et al. Biological characteristics and epidermal growth factor receptor tyrosine kinase inhibitors efficacy of EGFR mutation and its subtypes in lung adenocarcinoma. Pathol Oncol Res 2014;20:445-51.

21. Morelli MP, Cascone T, Troiani T, et al. Anti-tumor activity of the combination of cetuximab, an anti-EGFR blocking monoclonal antibody and ZD6474, an inhibitor of VEGFR and EGFR tyrosine kinases. J Cell Physiol 2006;208:344-53.

22. Pahl JH, Ruslan SE, Buddingh EP, et al. Anti-EGFR antibody cetuximab enhances the cytolytic activity of natural killer cells toward osteosarcoma. Clin Cancer Res 2012;18:432-41.

23. Wang $\mathrm{Y}$, He F, Zhang H, et al. Preparation and identification of an anti-idiotypic antibody antagonist (FG8) for EGFR that shows potential activity against liver cancer cells. Biotechnol Lett 2021;43:369-82.

24. Xu Q, Zhang X, Yue J, et al. Human TGFalpha-derived peptide TGFalphaL3 fused with superantigen for immunotherapy of EGFR-expressing tumours. BMC Biotechnol 2010;10:91.

(English Language Editor: C. Betlazar-Maseh)

Cite this article as: Ren K, Wang B, Qi Q. Development of a new EGFR antibody antagonist which exhibits potential biological effects against laryngeal cancer. Ann Transl Med 2021;9(12):964. doi: 10.21037/atm-21-1839 